Miami Nature Biotechnology Short Reports

TheScientificWorld (2001) 1(S3), 70SR

ISSN 1532-2246; DOI 10.1100/TSW.2001.110

\title{
B CELL PRECURSORS IN SENESCENT MICE EXHIBIT DECREASED MITOTIC RECRUITMENT, INCREASED APOPTOSIS, AND ALTERED EXPRESSION OF BCL-2 FAMILY MEMBERS
}

\author{
Richard L. Riley* and Erin M. Sherwood \\ Department of Microbiology and Immunology, University of Miami School of Medicine, \\ P.O. Box 016960 (R-138), Miami, FL 33101 \\ * rriley@med.miami.edu
}

INTRODUCTION. Senescence in inbred strains of mice affects lymphopoiesis within the bone marrow $(1,2)$. In the development of $\mathrm{B}$ lineage cells, old age is associated with a significant decline in pre-B cells. This could result from increased cell death (apoptosis) and/or decreased mitotic activity. We have determined the mitotic activity of B cell precursors from aged mice ex vivo and the kinetics of aged pro-B cell proliferation in vitro at the single-cell level in response to IL-7. Furthermore, we have assessed susceptibility of ex vivo aged B cell precursors to apoptosis and expression of the survival molecules $\mathrm{Bcl}-\mathrm{x}_{\mathrm{L}}$ and $\mathrm{Bcl}-2$ and the proapoptotic molecule Baxa in vitro.

METHODS. Senescent (18-27 mo. old) and young adult (2-8 mo. old) BALB/c mice were obtained from the National Institute of Aging colony. Mitotic activity among ex vivo B cell precursors was assessed by fluorescence flow cytometric DNA cell cycle analysis. Apoptosis among ex vivo B cell precursors was measured with time during short-term (0-4 hr.) culture by flow cytometry (3). Subpopulations of pro-B and pre-B cells (Hardy Fractions A, B, C, C', D [4]) were determined by 4-color flow cytometry. B cell precursors were expanded in vitro upon stimulation with rmIL-7 for one week. In vitro proliferation was monitored using CFSE staining. Bcl- $\mathrm{x}_{\mathrm{L}}$, Bcl-2, and Baxa proteins were determined by Western blot.

RESULTS. Ex vivo, pro-B/early pre-B cells from aged mice exhibited normal proportions in $\mathrm{S}$ + G2/M active cell cycle stages. Ex vivo pro-B cells (Hardy Fractions A, B) and pre-B cells (Hardy Fractions C, C', D) only exhibited enhanced apoptosis upon short-term culture in mice with very severe deficits in B lymphopoiesis. In vitro, aged pro-B cells generally showed limited expansion in response to IL-7 when compared to young pro-B cells. CFSE-labeling indicated that pro-B cells from aged mice underwent similar numbers of cell divisions over time, as did young pro-B cells; however, the numbers of expanded pro-B cells was decreased. The expansion of aged pro-B cells in response to IL-7 in vitro also correlated inversely with the ratio of the pro-apoptotic protein Baxa to the survival protein Bcl-2. Expansion of aged pro-B cells was favored by particularly low Baxa:Bcl-2 protein ratios. The survival protein $\mathrm{Bcl}-\mathrm{x}_{\mathrm{L}}$ was reduced in pro-B cells from the majority of aged mice, but this did not correlate with pro-B cell recovery in vitro.

DISCUSSION. Decreased pre-B cells in vivo and limited expansion of aged pro-B cells in vitro did not reflect poor proliferative capacity per se. More likely, aged mice have a lower frequency of pro-B/early pre-B cells, which are capable of undergoing extensive proliferation. 
A subset of aged mice with severe deficits in B lymphopoiesis exhibited increased susceptibility to apoptosis among their B cell precursors. Altered expression of both pro- and anti-apoptotic molecules was observed in aged B cell precursors. Expansion of aged pro-B cells may be dictated by both recruitment of B cell precursors into mitosis and their survival.

ACKNOWLEDGEMENTS. Supported by NIH grant AG 15474 to RLR.

\section{REFERENCES.}

1. $\quad$ Riley, R.L., Kruger, M.G., and Elia, J. (1991) Clin. Immunol. Immunopathol. 59, 301-313

2. Sherwood, E.M., Blomberg, B.B., Xu, W., Warner, C.A., and Riley, R.L. (1998) J. Immunol. 161, 4472- 4476

3. Lu, L., Chaudhury, P., and Osmond, D.G. (1999) J. Immunol. 162, 1931-1940

4. Hardy, R.R., Carmack, C.E., Shinton, S.A., Kemp, J.D., and Hayakawa, K. (1991) J. Exp. Med. 173, 1213-1225 

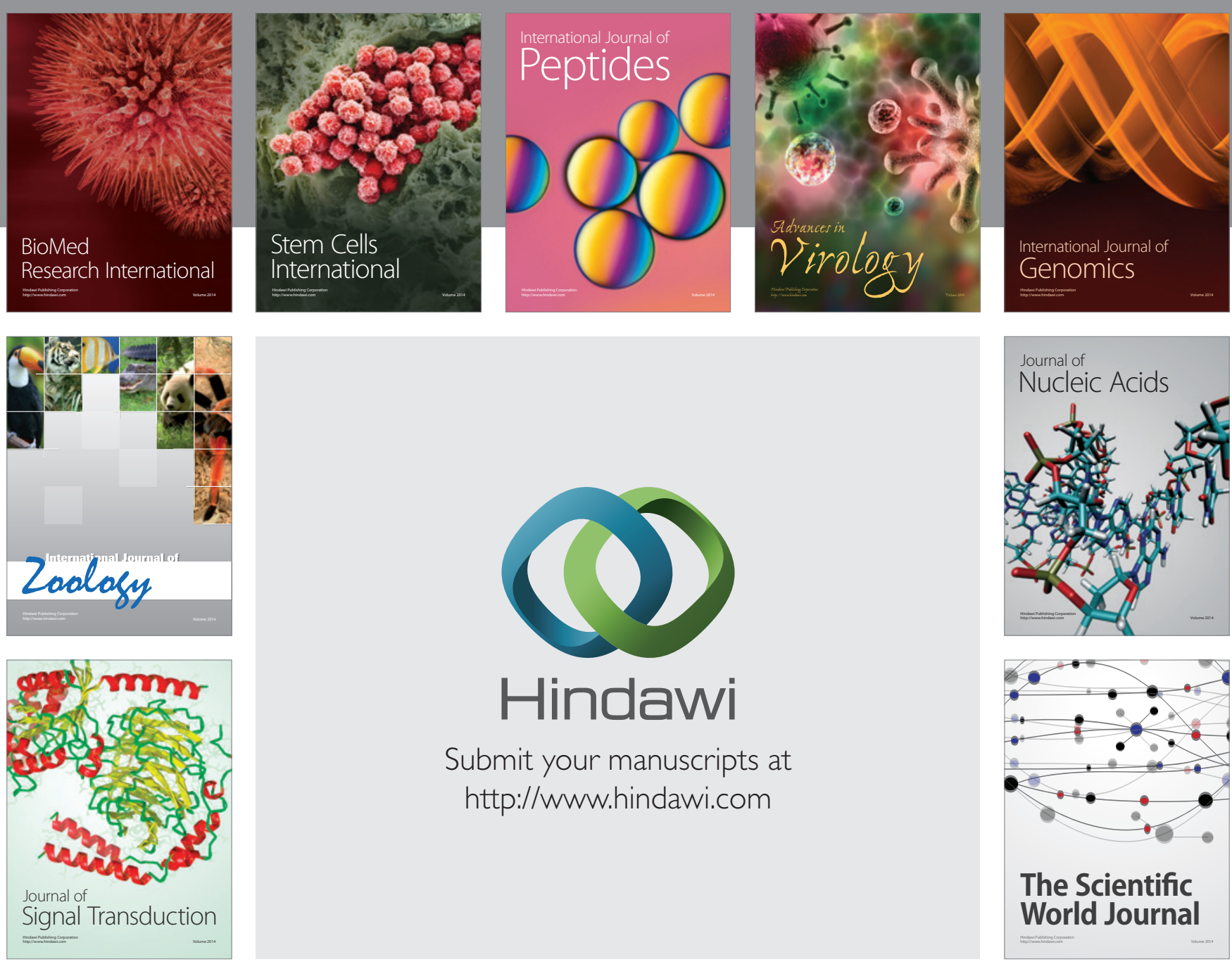

Submit your manuscripts at

http://www.hindawi.com
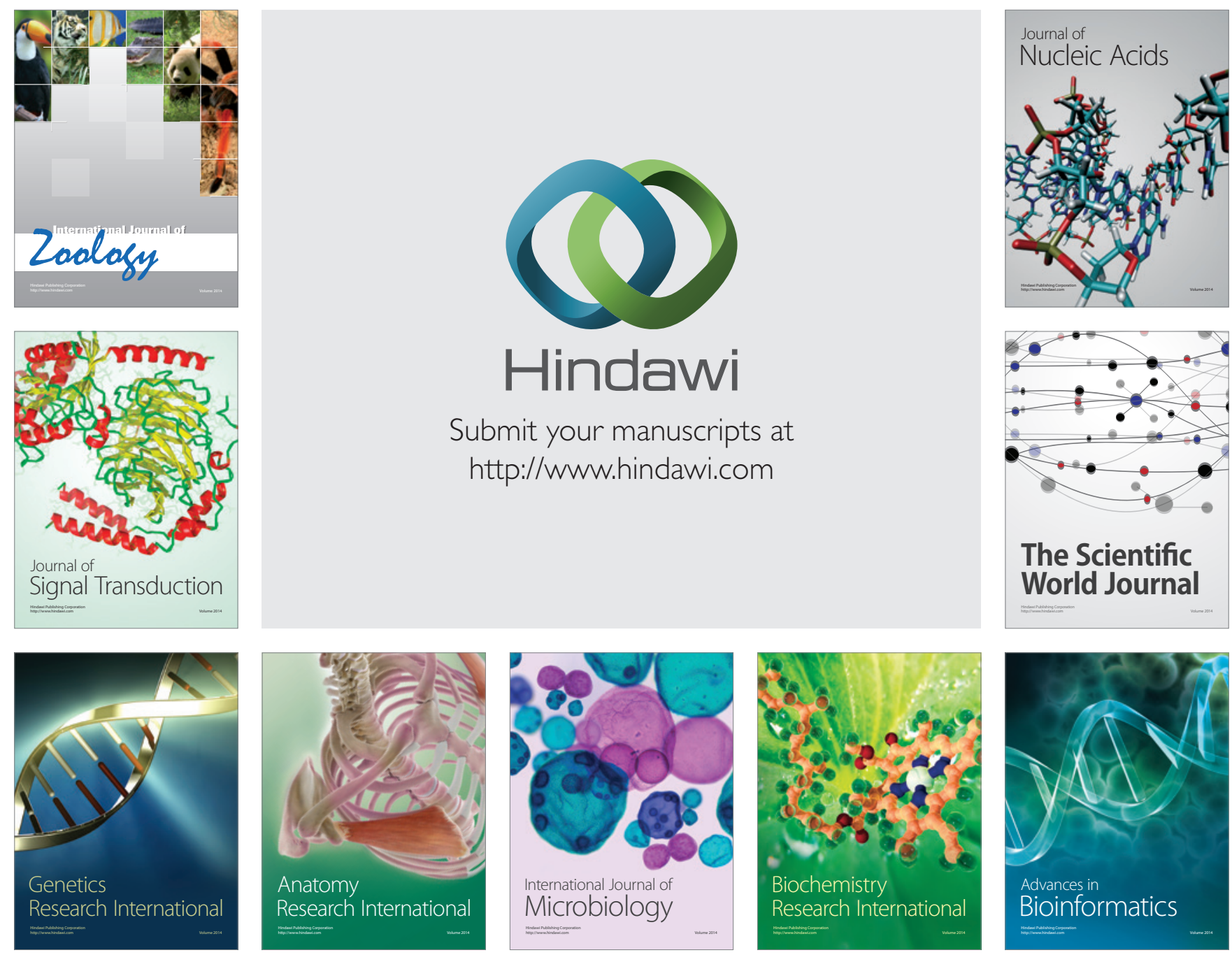

The Scientific World Journal
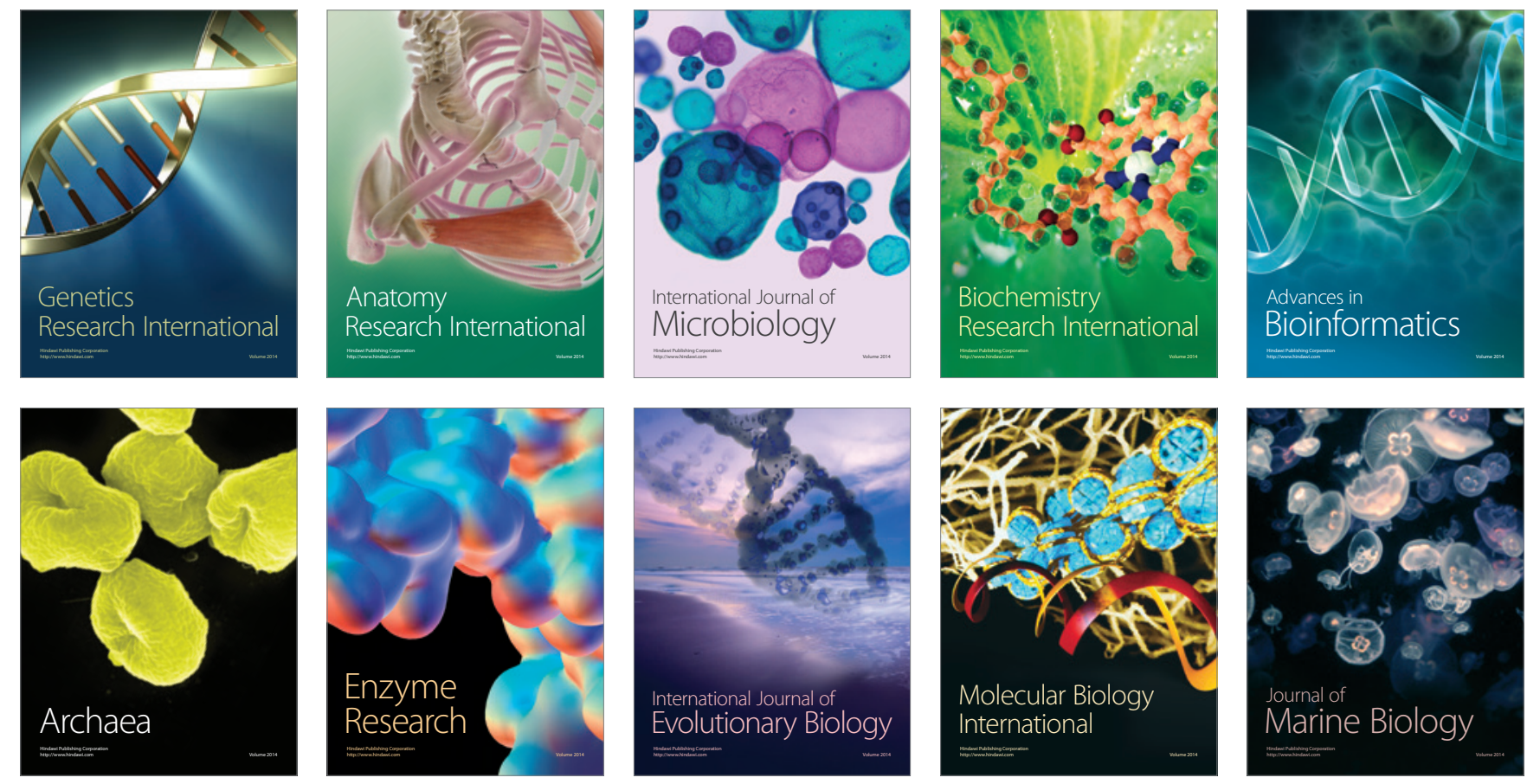